\title{
Asset Allocation in Stable and Unstable Times
}

Citation for published version (APA):

Bauer, R. M. M. J., Haerden, R., \& Molenaar, R. (2004). Asset Allocation in Stable and Unstable Times. The Journal of Investing, 13(3), 72-80. https://doi.org/10.3905/joi.2004.434554

Document status and date:

Published: 01/01/2004

DOI:

10.3905/joi.2004.434554

Document Version:

Publisher's PDF, also known as Version of record

\section{Please check the document version of this publication:}

- A submitted manuscript is the version of the article upon submission and before peer-review. There can be important differences between the submitted version and the official published version of record.

People interested in the research are advised to contact the author for the final version of the publication, or visit the DOI to the publisher's website.

- The final author version and the galley proof are versions of the publication after peer review.

- The final published version features the final layout of the paper including the volume, issue and page numbers.

Link to publication

\footnotetext{
General rights rights.

- You may freely distribute the URL identifying the publication in the public portal. please follow below link for the End User Agreement:

www.umlib.nl/taverne-license

Take down policy

If you believe that this document breaches copyright please contact us at:

repository@maastrichtuniversity.nl

providing details and we will investigate your claim.
}

Copyright and moral rights for the publications made accessible in the public portal are retained by the authors and/or other copyright owners and it is a condition of accessing publications that users recognise and abide by the legal requirements associated with these

- Users may download and print one copy of any publication from the public portal for the purpose of private study or research.

- You may not further distribute the material or use it for any profit-making activity or commercial gain

If the publication is distributed under the terms of Article $25 \mathrm{fa}$ of the Dutch Copyright Act, indicated by the "Taverne" license above, 


\title{
Asset Allocation in Stable and Unstable Times
}

\author{
Rob Bauer, Roul Haerden, and Roderick Molenaar
}

\section{ROB BAUER \\ is an associate professor at Maastricht University and head of the research department at ABP Invest- ments in The Netherlands. r.bauer@abp.nl \\ ROUL HAERDEN \\ is a portfolio manager at ABP Investments in The \\ Netherlands. \\ r.haerden@abp.nl}

RODERICK MOLENAAR is a senior researcher at $\mathrm{ABP}$ Investments in The

Netherlands.

r.molenaar@abp.nl

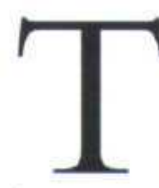

raditional portfolio techniques often fail in times of financial stress or instability, when volatilities and correlations tend to increase. When it is most needed, the cushioning effect of portfolio diversification on total risk is highly overstated. When investors use a mean-variance optimization procedure to construct portfolios, they face the negative effects of estimation risk. This kind of risk emerges when the expected risk and return parameters deviate from the true generated figures in a particular period. The result is suboptimal active positions, which can lead to lower returns.

Michaud [1989] states that mean-variance optimized portfolios are "estimation error maximizers." Mean-variance optimization significantly overweights securities that have high estimated returns, negative correlations, and small variances, and underweights those with low estimated returns, positive correlations, and large variances. When in times of financial distress, both volatilities and correlations tend to temporarily move away from their long-run averages, the negative effects of estimation risk increase even more.

Chow et al. [1999] address this problem by introducing a procedure that identifies multivariate outliers. These outliers can be used to construct portfolios that give a better representation of risk during unstable and volatile times. The authors show there is a big difference in terms of optimal weights between the mean-variance model that uses the full covari- ance matrix and one that distinguishes some kind of regime, in this case good or bad times.

Chow et al. [1999] present optimal portfolio weights, but provide no evidence on the performance and risk of the portfolio. We test whether the distinction in risk characteristics between good and bad times leads to better returns than a standard optimization procedure that uses the full covariance matrix. After all, the investor is interested only in a positive information ratio (IR).

We split global portfolio data into quiet and turbulent times in order to uncover the specific risk characteristics that are present in such times. Comparison of two strategies to generate optimal portfolios under a regimeswitching strategy lets us test the theory. Transaction costs eat up much of the excess returns.

\section{MULTIVARIATE OUTLIER APPROACH}

In turbulent times, assets react quite differently from quiet times. Equities, for instance, have a higher risk and correlation in unstable times. This can affect the risk of both institutional and private investor portfolios. Portfolio risk increases with increasing volatilities and correlations.

Chow et al. [1999] show how to capture these effects and use them to get better insight into the risks of a portfolio. They use a statistical procedure, the distance function, to determine whether a period can be seen as stable or unstable. They do this by identifying 
multivariate outliers over a certain time. These outliers represent a set of contemporaneous (asset) returns that are rather unusual.

For example, one asset return at time t may deviate so far from its mean that it qualifies the whole set of asset returns at time $t$ as an outlier. Or, a pair of highly correlated returns may behave so differently from each other in a period that they can be regarded as unusual.

The appendix describes the distance function.

This method allows calculation of both a stable and a stress covariance matrix based on normal and outlier observations. These matrices have their own risk characteristics that can be used in the optimization process. The weighted sum of these two covariance matrices is equal to the original full-sample covariance matrix. Such a regimeswitching methodology results in different optimal portfolio weights from the standard mean-variance optimization procedure.

Chow et al. [1999] do not show whether this technique can add value for investors in terms of performance. Difference in portfolio weights could produce better performance in both stable and bad times, because in bad times the regime-switching strategy would allocate a higher portion of the portfolio to a safe haven such as bonds.'

\section{DATA AND SUMMARY STATISTICS}

To get a feeling for the kind of risk characteristics embodied in several assets, we apply this method to calculate the risk parameters for a six-asset portfolio from January 1976 through December 2002. Exhibit 1 displays the six asset classes in the portfolio. It can be considered a realistic approximation of the portfolios many institutional investors use as their benchmark.

The assets in the portfolio are domestic equity (S\&P 500 from an U.S. investor's point of view); foreign equities (MSCI Japan and MSCI Europe); domestic bonds (Lehman U.S. Aggregate); commodities (Goldman Sachs Commodity Index); and real estate (NAREIT All). The foreign equities are unhedged, implying that currency returns are included in the total returns of these assets. Throughout the analysis we use this constant-mix portfolio as a benchmark against which to measure our optimization strategies.

Exhibit 2 displays the risk characteristics for both the full-sample portfolio and the portfolio that distinguishes good and bad times. We identify bad times (i.e., the multivariate outliers) by selecting the outer $10 \%$ of the total multivariate distribution. This means that the inside observations ( $90 \%$ of the distribution) represent the good
ExH I B I T 1

\section{Benchmark Used for Optimization}

\begin{tabular}{lr}
\hline Index & Weight \\
\hline S\&P 500 & $20.00 \%$ \\
MSCI Japan & $10.00 \%$ \\
MSCI Europe & $20.00 \%$ \\
Lehman U.S. Aggregate & $40.00 \%$ \\
Goldman Sachs Commodity Index (GSCI) & $5.00 \%$ \\
NAREIT All & $5.00 \%$ \\
\hline
\end{tabular}

or stable risk regimes, while the other observations $(10 \%$ of the distribution) form the bad or unstable regimes. Note that observations in an unstable regime are not necessarily negative outliers; there may be positive outliers too.

Exhibit 2 indicates that correlations between assets in the regime-switching strategy differ substantially from the standard full-sample methodology. The correlation between the Lehman U.S. Aggregate and the other assets is higher in good times than the same correlations for the full-sample matrix. The correlation between the Lehman U.S. Aggregate and the MSCI Europe increases from 0.21 to 0.29. The same holds for the Lehman U.S. Aggregate versus the S\&P 500 (from 0.27 to 0.36 ). The correlations between real estate and equities (U.S. and Europe) are lower (from 0.53 to 0.42 for the U.S. and from 0.38 to 0.30 for Europe).

The opposite result is seen in comparison of correlations between bad times and the full-sample period. The correlations between fixed-income and the other assets, except MSCI Japan, decline dramatically (from 0.27 to 0.12 for the S\&P 500 versus fixed-income). Correlations between commodities and foreign equity and real estate also decline.

Declining correlations between equities and fixedincome in times of stress are also found by Gulko [2002]. He shows that in times of financial stress or contagion correlations between equities and bonds decouple from a positive relation into a negative one, and thus enhance the benefits of portfolio diversification. Volatilities also are dependent on the regime. Volatilities in bad times are $50 \%$ to $80 \%$ higher (e.g. fixed-income and U.S. equities) than in the full-sample statistics. In good times, volatilities can drop to $80 \%$ of the full-sample number (e.g., real estate).

Exhibit 2 does not confirm the general view that correlations between equities tend to increase in bad times. Correlations are generally expected to increase because there is a greater probability in bad times of contagion across markets (recall the Asian crisis in 1998 and the effects of the attacks on September 11, 2001). 


\section{EXHIBIT 2}

\section{Risk Features for Different Regimes}

\begin{tabular}{|c|c|c|c|c|c|c|}
\hline \multicolumn{7}{|l|}{ Full Sample Period } \\
\hline Correlations + Risks & S\&P 500 & MSCI JAPAN & MSCI EUROPE & LEHM US AGGR GSCI & NAREIT ALL & Return \\
\hline S\&P 500 & $15.5 \%$ & & & & & $13.2 \%$ \\
\hline MSCI JAPAN & 0.30 & $23.1 \%$ & & & & $11.3 \%$ \\
\hline MSCI EUROPE & 0.62 & 0.49 & $16.4 \%$ & & & $12.7 \%$ \\
\hline LEHM US AGGR & 0.27 & 0.11 & 0.21 & $6.10 \%$ & & $9.1 \%$ \\
\hline $\mathrm{GSCl}$ & 0.04 & 0.12 & 0.12 & $16.60 \%$ & & $9.4 \%$ \\
\hline NAREIT ALL & 0.53 & 0.14 & 0.38 & 0.06 & $12.9 \%$ & $12.6 \%$ \\
\hline \multicolumn{7}{|l|}{ Good Times Regime } \\
\hline Correlations + Risks & S\&P 500 & MSCI JAPAN & MSCI EUROPE & LEHM US AGGR GSCI & NAREIT ALL & Return \\
\hline S\&P 500 & $13.0 \%$ & & & & & $12.8 \%$ \\
\hline MSCI JAPAN & 0.26 & $20.9 \%$ & & & & $14.4 \%$ \\
\hline MSCI EUROPE & 0.61 & 0.47 & $14.2 \%$ & & & $16.4 \%$ \\
\hline LEHM US AGGR & 0.36 & 0.07 & 0.29 & $5.0 \%$ & & $8.7 \%$ \\
\hline $\mathrm{GSCl}$ & 0.03 & 0.15 & 0.19 & $14.1 \%$ & & $8.3 \%$ \\
\hline NAREIT ALL & 0.42 & 0.10 & 0.30 & 0.06 & $10.0 \%$ & $13.2 \%$ \\
\hline \multicolumn{7}{|c|}{ Bad Times Regime ( $10 \%$ boundary) } \\
\hline Correlations + Risks & S\&P 500 & MSCI JAPAN & MSCI EUROPE & LEHM US AGGR GSCI & NAREIT ALL & Return \\
\hline S\&P 500 & $27.0 \%$ & & & & & $11.5 \%$ \\
\hline MSCI JAPAN & 0.37 & $34.5 \%$ & & & & $-11.8 \%$ \\
\hline MSCI EUROPE & 0.67 & 0.53 & $26.4 \%$ & & & $-14.6 \%$ \\
\hline LEHM US AGGR & 0.12 & 0.19 & 0.12 & $11.2 \%$ & & $11.8 \%$ \\
\hline $\mathrm{GSCl}$ & 0.09 & 0.09 & 0.02 & $28.8 \%$ & & $20.6 \%$ \\
\hline NAREIT ALL & $0.67^{*}$ & 0.19 & 0.52 & 0.28 & $24.6 \%$ & $5.3 \%$ \\
\hline
\end{tabular}

*Denotes a significant difference fon a $10 \%$ level) betueen the correlation of good and bad times.

E X H I B I T 3

Transition Matrix for Outer $10 \%$ of Distribution

\begin{tabular}{|l|ccc|}
\hline & \multicolumn{3}{|c|}{ From Current Regime } \\
\hline To & & Good & Bad \\
\cline { 2 - 4 } Next & Good & $90 \%$ & $73 \%$ \\
Regime & Bad & $10 \%$ & $27 \%$ \\
\hline
\end{tabular}

Longin and Solnik [2001] find the correlation of large negative returns in international stock markets to be much greater than would be expected by multivariate normality. These findings also hold for the correlation of large positive returns, which implies that correlations among equities in outlier situations behave differently from expected multivariate normality.

Exhibit 3 shows the historical transition probabilities of going from one regime to another the next month. The definitions of an unstable regime in this example are the outliers based on the outer boundary that excludes $10 \%$ of the multivariate distribution.
The chances in this transition matrix are of course highly dependent on the cutoff value taken to identify a unstable regime. This means that the number of outliers we should expect from a theoretical point of view (i.e., the cutoff value used to define a multivariate outlier) approximates the outliers that occurred empirically. Exhibit 3 shows that when a unstable regime occurs, there is a high probability of going into a stable regime the next month $(73 \%)$.

\section{PORTFOLIO OPTIMIZATION STRATEGIES}

To implement the regime-switching technique from an investor's point of view, we apply an out-of-sample backtesting procedure. We conduct a backtest in mean tracking error space, as most institutional investors have to comply with a particular benchmark. We calculate the excess return of two portfolios created using different strategies to derive the optimal mix in order to determine the added value of the regime-switching technique. 
EX Н I В I T 4

Return and Risk Characteristics-No Transaction Costs

\begin{tabular}{|c|c|c|c|c|c|c|}
\hline \multicolumn{2}{|c|}{ Standard Optimization Strategy } & \multicolumn{5}{|c|}{ Regime-Switching Strategy } \\
\hline \multirow{2}{*}{$\frac{\text { Ex Ante Tracking Error }}{\% \text { Outer Boundary }}$} & $1 \%$ & \multicolumn{5}{|c|}{$1 \%$} \\
\hline & & $50 \%$ & $40 \%$ & $30 \%$ & $20 \%$ & $10 \%$ \\
\hline \multicolumn{7}{|l|}{ Descriptive Statistics } \\
\hline Excess Return & $0.24 \%$ & $0.02 \%$ & $-0.03 \%$ & $-0.14 \%$ & $0.21 \%$ & $0.43 \%$ \\
\hline Ex Post Tracking Error & $1.17 \%$ & $1.12 \%$ & $1.12 \%$ & $1.18 \%$ & $1.11 \%$ & $1.13 \%$ \\
\hline Information Ratio & 0.20 & 0.02 & -0.03 & 0.12 & 0.19 & 0.38 \\
\hline Ex Ante Tracking Error & $2 \%$ & \multicolumn{5}{|c|}{$2 \%$} \\
\hline \% Outer Boundary & & $50 \%$ & $40 \%$ & $30 \%$ & $20 \%$ & $10 \%$ \\
\hline \multicolumn{7}{|l|}{ Descriptive Statistics } \\
\hline Excess Return & $0.74 \%$ & $0.16 \%$ & $0.03 \%$ & $0.26 \%$ & $0.44 \%$ & $1.12 \%$ \\
\hline Ex Post Tracking Error & $2,21 \%$ & $1.89 \%$ & $2.01 \%$ & $2.10 \%$ & $1.96 \%$ & $2.05 \%$ \\
\hline Information Ratio & 0.34 & 0.08 & 0.02 & 0.13 & 0.22 & 0.55 \\
\hline Ex Ante Tracking Error & $3 \%$ & \multicolumn{5}{|c|}{$3 \%$} \\
\hline \% Outer Boundary & & $50 \%$ & $40 \%$ & $30 \%$ & $20 \%$ & $10 \%$ \\
\hline \multicolumn{7}{|l|}{ Descriptive Statistics } \\
\hline Excess Return & $0.70 \%$ & $0.31 \%$ & $0.13 \%$ & $0.45 \%$ & $0.36 \%$ & $1.04 \%$ \\
\hline Ex Post Tracking Error & $2.67 \%$ & $2.21 \%$ & $2.41 \%$ & $2.43 \%$ & $2.19 \%$ & $2.52 \%$ \\
\hline Information Ratio & 0.26 & 0.14 & 0.06 & 0.19 & 0.16 & 0.41 \\
\hline
\end{tabular}

The first portfolio optimization strategy, also called the standard optimization strategy, uses a full historical sample to generate the input parameters. The second strategy tries to identify how much value can be added if one already knows what kind of regime will occur next month. This strategy thus assumes perfect foresight with respect to the occurrence of either a good or an unstable regime.

The input parameters consist of the historical risk and return numbers characteristic of a quiet or an unstable regime. This means we use only these simple historical return and risk characteristics to forecast the future.

The backtest procedure for the standard portfolio works as follows:

- At the end of each month, we construct an optimal portfolio to be measured against the benchmark in Exhibit 1. The optimal portfolio is derived using a 120-month historical rolling window. This means that on December 31, 1985, we use a historical dataset running from January 1976 through December 1985. From this dataset we calculate historical returns, standard deviations, and correlations, and use this as a forecast to construct our optimal portfolio weights for the next month. A maximum deviation of 10 percentage points from the benchmark weights is allowed, together with a maximum risk contribution to the tracking error of $33 \%$. Short-selling is prohibited.

- This portfolio is held for one month. At the end of the month, the excess return of the portfolio is calculated.

- At the close of the month, the procedure is repeated, and a new portfolio is generated. We follow this procedure from January 1986 through December 2002.

The procedure for the second strategy differs in a few respects. First, we assume we know what kind of regime will occur the next month. This does not mean we know what the returns will be; it tells us only whether a good or an unstable regime will occur. Second, the input parameters for this strategy are the historical return vector and covariance matrix that represent the accompanying regime. We calculate the returns of both strategies with and without transaction costs.?

\section{EMPIRICAL RESULTS}

We compare the two strategies for several cutoff values and tracking errors. A cutoff value can be defined as an $\mathrm{X} \%$ boundary of the multivariate outliers. Exhibit 4 presents the results in terms of excess return and risk for portfolios with cutoff values ranging from $10 \%$ to $50 \%$ and tracking errors from $1 \%$ to $3 \%$. In these results, transac- 
EX ХНІВІт 5

\section{Information Ratios for Regime-Switching Strategies with Perfect Foresight}

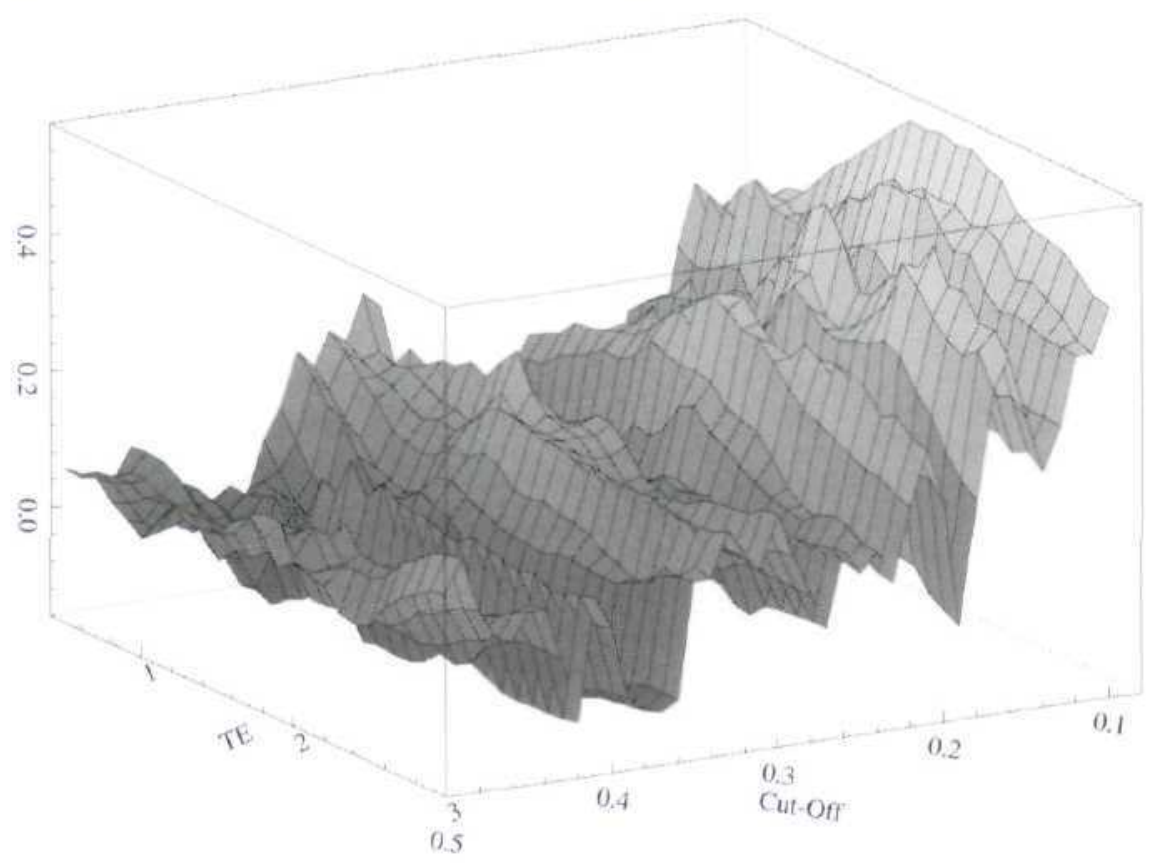

tion costs are not yet taken into account.

There are a few differences between the standard optimization strategy and the perfect foresight strategy. First, it is of great importance to choose the right multivariate boundary. If the boundary is set too high (e.g., $20 \%$ or higher), the differences between the stable and the unstable covariance matrix become small. The reason for declining information ratios at higher boundaries can be found in smaller differences in the risk parameters.

If the boundary for outliers increases, more observations are included in the bad times regime. As a result, there is less of a difference between correlations and standard deviations. This means there are smaller differences in bets derived using the regime-switching strategy or the standard optimization strategy, and thus more similar performance, Only strategies with low cutoff values (e.g., $10 \%$ ) result in higher information ratios than the standard optimization strategy.

Second, the performance (in terms of IR) of the perfect foresight strategy in most cases increases with the ex ante risk level. Notable exceptions are the $10 \%$ and $20 \%$ cutoff values with ex ante risk levels exceeding $2 \%$. This is most likely because of the larger bets that can be taken at higher risk levels (until the bets reach their imposed constraints). Ultimately, the ex post realized risk is higher than the ex ante expected risk.
The reason is that we have to deal with the negative effects of estimation risk. This is the risk that the true return and risk parameters are different from the expectations at the beginning of the period, which can lead to different portfolio weights.

Satchell and Hwang [2001] explain that ex ante and ex post tracking error always differ, since portfolio weights are ex post stochastic in nature. For portfolios with a maximum ex ante risk of $3 \%$, the realized risk is lower, however, mainly because of restrictions on the maximum size of a bet (10\%) and the short-selling restrictions.

Exhibit 5 shows all information ratios of the regimeswitching strategy, again in the absence of transaction costs with perfect foresight. The plot shows there is a negative relation between the information ratio and the cutoff value. When the cutoff value rises, the information ratio declines, and vice versa. With respect to the ex ante risk level, the information ratio shows a slight U-shape for high cutoff values, stays roughly the same for medium cutoff values, and shows a reverse $U$-shape for low cutoff values.

Exhibit 6 reveals that the results after transaction costs change dramatically. Only the strategy with a maximum ex ante tracking error of $2 \%$ and a cutoff value of $10 \%$ shows marginally better performance than the standard strategy. The switching strategy has a higher turnover 


\section{EXHIBIT 6}

\section{Return and Risk Characteristics-With Transaction Costs}

\begin{tabular}{|c|c|c|c|c|c|c|}
\hline \multicolumn{2}{|c|}{ Standard Optimization Strategy } & \multicolumn{5}{|c|}{ Regime-Switching Strategy } \\
\hline Ex Ante Tracking Error & $1 \%$ & & & $1 \%$ & & \\
\hline \% Outer Boundary & & $50 \%$ & $40 \%$ & $30 \%$ & $20 \%$ & $10 \%$ \\
\hline \multicolumn{7}{|l|}{ Descriptive Statistics } \\
\hline Excess Return & $0.22 \%$ & $-0.35 \%$ & $-0.40 \%$ & $-0.21 \%$ & $-0.12 \%$ & $0.20 \%$ \\
\hline Ex Post Tracking Error & $1.17 \%$ & $1.12 \%$ & $1.12 \%$ & $1.17 \%$ & $1.10 \%$ & $1.13 \%$ \\
\hline Information Ratio & 0.18 & -0.31 & -0.36 & -0.18 & -0.11 & 0.18 \\
\hline Ex Ante Tracking Error & $2 \%$ & \multicolumn{5}{|c|}{$2 \%$} \\
\hline \% Outer Boundary & & $50 \%$ & $40 \%$ & $30 \%$ & $20 \%$ & $10 \%$ \\
\hline \multicolumn{7}{|l|}{ Descriptive Statistics } \\
\hline Excess Return & $0.68 \%$ & $-0.41 \%$ & $-0.62 \%$ & $-0.34 \%$ & $-0.15 \%$ & $0.68 \%$ \\
\hline Ex Post Tracking Error & $2.21 \%$ & $1.89 \%$ & $2.02 \%$ & $2.08 \%$ & $1.96 \%$ & $2.04 \%$ \\
\hline Information Ratio & 0.31 & -0.22 & -0.31 & -0.16 & -0.08 & 0.33 \\
\hline Ex Ante Tracking Error & $3 \%$ & \multicolumn{5}{|c|}{$3 \%$} \\
\hline \% Outer Boundary & & $50 \%$ & $40 \%$ & $30 \%$ & $20 \%$ & $10 \%$ \\
\hline \multicolumn{7}{|l|}{ Descriptive Statistics } \\
\hline Excess Return & $0.63 \%$ & $-0.26 \%$ & $-0.56 \%$ & $-0.19 \%$ & $-0.30 \%$ & $0.52 \%$ \\
\hline Ex Post Tracking Error & $2.67 \%$ & $2.21 \%$ & $2.41 \%$ & $2.41 \%$ & $2.17 \%$ & $2.50 \%$ \\
\hline Information Ratio & & -0.12 & -0.23 & -0.08 & -0.14 & 0.21 \\
\hline
\end{tabular}

(and thus additional transaction costs) than the standard strategy because large shifts between assets occur here more frequently due to the changing regimes. The information ratios of the switching strategy are positive only when cutoff values are very low (i.e., under $10 \%$ ).

Exhibit 7 graphs the information ratios for the regimeswitching strategy after transaction costs. It shows that most information ratios are close to zero or even negative.

A comparison of Exhibits 5 and 7 shows that the potential advantage of using different risk input parameters is reduced by the high transaction costs resulting from this strategy.

To provide more insight into the behavior of portfolio weights through time, Exhibit 8 compares portfolio weights of the regime-switching strategy with those of the standard optimization strategy. In turbulent times (such as 2000-2002), the regime-switching strategy allocates on average more to fixed-income, real estate, and commodities than the standard strategy. The strategy also favors Japanese equities in these times. The opposite occurs in good times. In these periods, European equities receive more exposure than in the standard strategy. The weights of fixed-income, commodities, and real estate show the opposite behavior.
The advantages of the regime-switching strategy are most visible when we look at one specific month that can be regarded as an outlier. Exhibit 9 shows, for example, the differences in portfolio weights for such a multivariate outlier month, September 2002, based on a cutoff strategy of $10 \%$. In this month, financial markets all over the world dropped substantially. The regime-switching strategy, however, had more exposure to fixed-income in this month, which resulted in outperformance of 252 basis points over the standard optimization strategy.

Finally, we calculate the cumulative total excess performance of the regine-switching strategy over time. These results are displayed in Exhibit 10. The actual outliers during this period were a little higher than ex ante expected $(10 \%)$. This is in line with the findings in Chow et al. [1999]. On average $12.3 \%$ of the observations were identified as outliers. The first two years of the 1990s in particular show a lot of turbulent months.

Note that a bad or turbulent month does not necessarily mean that the return in that month is negative, because no distinction is made between positive and negative outliers. ${ }^{3}$ The cumulative excess return (against the standard optimization strategy) of the bad times alone is 


\section{EXH I I T 7}

Information Ratios for Regime-Switching Strategies with Perfect Foresight and Transaction Costs

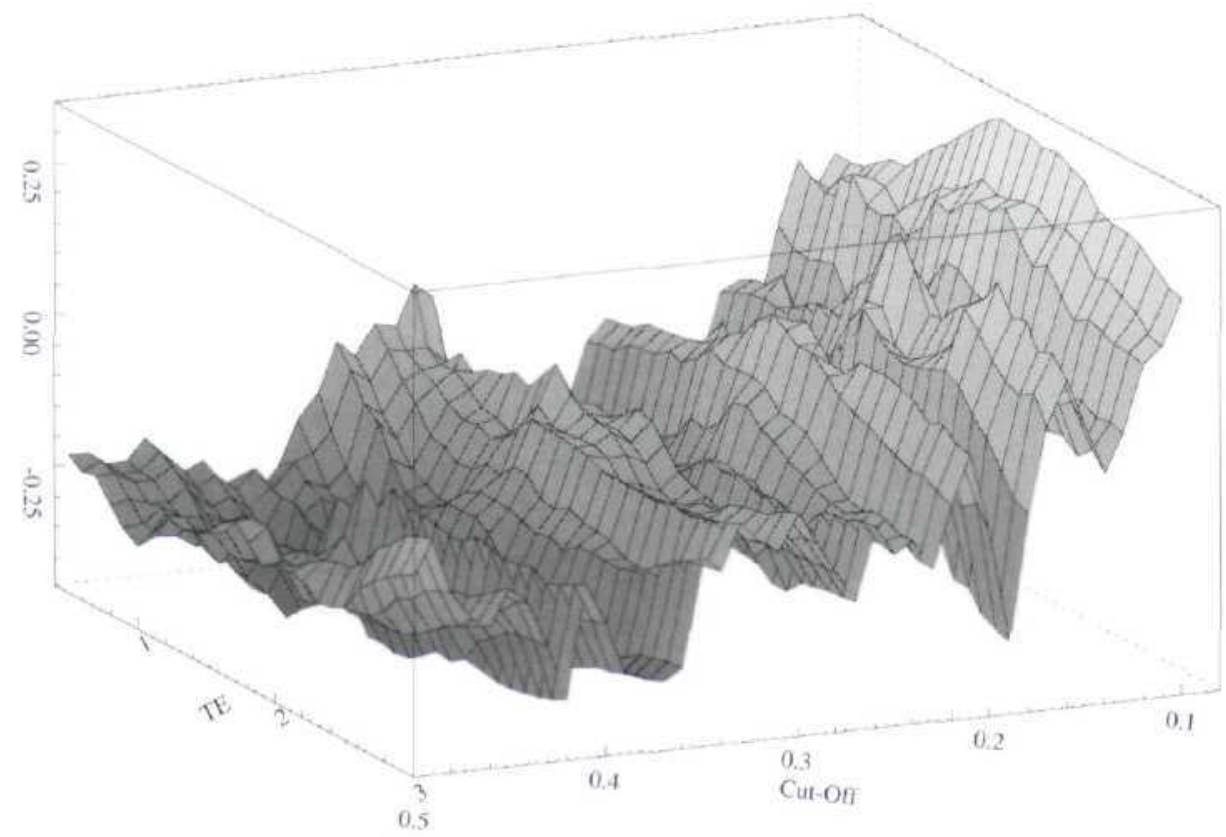

\section{EXHIBIT 8}

Differences in Weights Between Standard Optimization Strategy and Regime-Switching Strategy
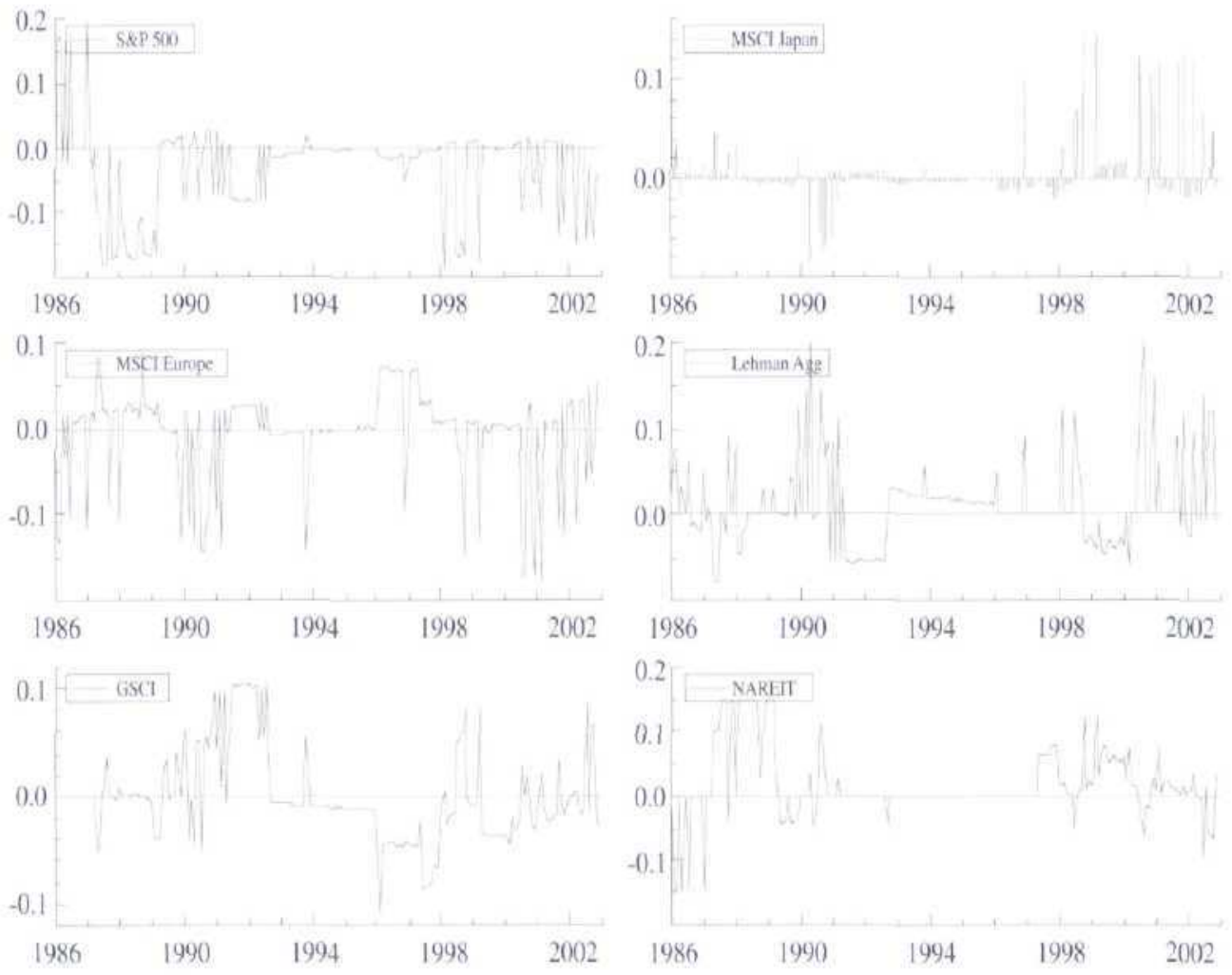
$10.12 \%$, while the good times earned $-3.63 \%$ on a cumulative basis.

Making a distinction between turbulent and less turbulent times seems to pay off. Mostly in bad times, the asset mix of the regime-switching strategy differs significantly from that of the standard optimization strategy. This results in more exposure to fixed-income, commodities, and real estate, which may be seen as a kind of safe haven.

\section{CONCLUDING COMMENTS}

In turbulent times we see a tendency of changing correlations and volatilities among assets. Safe havens such as bonds, commodities, and real estate can be identified in these stressful periods. The latter asset classes (together with Japanese equities) are usually overweighted, while European and U.S. equities are underweighted in these periods.

We have demonstrated, under the assumption of perfect foresight with regard to the prevailing regime, how much value can be added in terms of information
Exнівіт 9

Weight Differences Between Regime-Switching Portfolio and Standard Optimization PortfolioSeptember 2002

\begin{tabular}{lr}
\hline Index & Difference \\
\hline S\&P 500 & $-11.72 \%$ \\
MSCI Japan & $4.12 \%$ \\
MSCI Europe & $-5.40 \%$ \\
Lehman U.S. Aggregate & $11.85 \%$ \\
Goldman Sachs Commodity Index (GSCI) & $6.73 \%$ \\
NAREIT All & $-5.59 \%$ \\
& \\
Excess Return September 2002 & $+252 \mathrm{bp}$ \\
\hline
\end{tabular}

ratio by using a regime-switching strategy instead of the standard mean-variance optimization strategy.

There is an advantage, however, only when very low cutoff values are used. After accounting for transaction costs, a substantial part of the positive excess return

\section{EXH I В I T 10}

\section{Excess Return in Bad Times and Good Times}
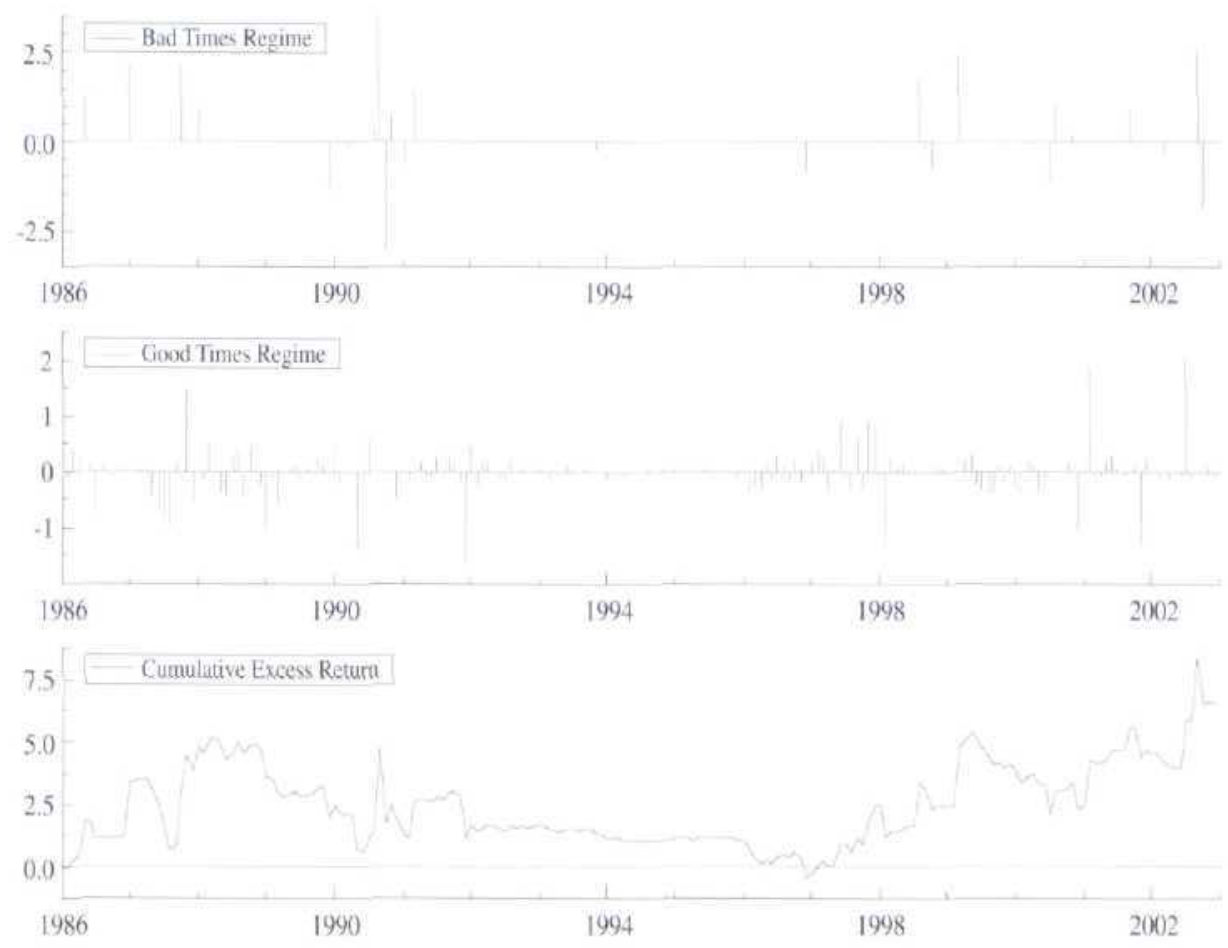
disappears. This means that in the real world the information ratio will probably be even lower - investors obviously do not have perfect foresight.

\section{APPENDIX}

\section{Explanation of Distance Function Used to Find Multivariate Outliers}

A multivariate outlier is identified when in a certain month the whole set of returns diverges from a prespecified statistic called the distance function, calculated as follows:

$$
\text { Distance }_{\mathrm{t}}=\left(\mathrm{X}_{\mathrm{t}}-\mathrm{U}_{\mathrm{t}}\right) \Sigma^{-1}\left(\mathrm{X}_{\mathrm{t}}-\mathrm{U}_{\mathrm{t}}\right)^{\prime}
$$

where:

$$
\begin{aligned}
\text { Distance }_{t}= & \text { vector distance from multivariate mean at } \\
& \text { time } t ; \\
X_{t} & =\text { vector of series at time } t ; \\
U_{t} & =\text { mean vector of return series } X_{t} ; \text { and } \\
\Sigma_{t} & =\text { covariance matrix of return series } X_{t} .
\end{aligned}
$$

We assume that the return series $\mathrm{X}_{\text {t }}$ is normally distributed with a mean return vector of $\mathrm{U}_{\mathrm{t}}$ and a covariance matrix of $\Sigma$. The distance statistic has a chi-square distribution with degrees of freedom equaling the number of return series. The chi-square value for a six-asset portfolio that identifies a multivariate outlier when it exceeds, for example, the outer $10 \%$ of the distribution is 10.64 . When the value of the distance function for a certain return series $(\mathrm{X})$ is higher than this prespecified tolerance level, the return series for month $t$ represents a multivariate outlier.

\section{ENDNOTES}

The authors gratefully acknowledge the comments of Jeroen Derwall, Mark Kritzman, Harry Markowitz and of their colleagues.

'In the multivariate outlier approach, bad times can be periods with both extremely negative and positive returns, but bad times generally occur in periods with negative returns.

${ }^{2}$ Single-trip transaction costs of 25 basis points per month are assumed for changing portfolio weights in the optimization.

${ }^{3}$ Zimmermann, Drobetz, and Oertmann [2003] also note this shortcoming.

\section{REFERENCES}

Chow, G., E. Jacquier, M. Kritzman, and K. Lowry. "Optimal Portfolios in Good and Bad Times." Financial Analysts Journal, May/June 1999, pp. 65-73.

Gulko, L. "Decoupling." The Journal of Portfolio Management, Spring 2002, pp. 59-66.

Longin, F., and B. Solnik. "Correlation Structure of International Equity Markets During Extreme Volatile Periods." Journal of Finance, 56, 2 (2001), pp. 649-679.

Michaud, R.O. "The Markowitz Optimization Enigma: Is Optimized Optimal?" Financial Analysts Journal, pp. 31-42.

Satchell, S.E., and S. Hwang. "Tracking Error: Ex Ante versus Ex Post Measures." Journal of Asset Management, 2, 3 (December 2001), pp. 241-246.

Zimmermann, H., W. Drobetz, and P. Oertmann. Global Asset Allocation. Hoboken, New Jersey: John Wiley \& Sons, 2003.

To order reprints of this article, please contact Ajani Malik at amalik@iijournals.com or 212-224-3205. 
() Euromoney Institutional Investor PLC. This material must be used for the customer's internal business use only and a maximum of ten (10) hard copy print-outs may be made. No further copying or transmission of this material is allowed without the express permission of Euromoney Instituitonal Investor PLC. Copyright of Journal of Portfolio Management is the property of Euromoney Publications PLC and its content may not be copied or emailed to multiple sites or posted to a listserv without the copyright holder's express written permission. However, users may print, download, or email articles for individual use. 